\title{
An approach to olfactory impairments in the general practice setting
}

Fred Chuang, Rohan Arasu, Benjamin Wallwork

\section{Background}

Olfactory impairment is a common condition, particularly in the geriatric population, which can be underrecognised as a result of clinician and patient unfamiliarity.

\section{Objective}

The aim of this article is to bring awareness to olfactory impairment, describe the common aetiologies and provide a framework for its diagnosis and management in the general practice setting, including advice about when to refer.

\section{Discussion}

A thorough history and examination can often elucidate the common causes, which include rhinosinusitis, upper respiratory tract viral illnesses and head trauma. Rhinosinusitis is the most readily managed aetiology in the general practice setting, with other causes often requiring multidisciplinary input. Chronic olfactory impairment is often irreversible and can be a debilitating condition, causing disability in day-to-day living and impairing quality of life.
OLFACTORY IMPAIRMENT is a common disorder that is underrecognised and underdiagnosed because of general unfamiliarity among clinicians and patients. Olfaction is a vital sensory input that integrates the olfactory, gustatory and trigeminal systems. It provides information on smell and the palatability of consumed food. Sense of smell can be described as elevated (hyperosmic), normal (normosmic), diminished (hyposmic) and absent (anosmic). Rarer forms of olfactory impairment include parosmia (altered perception) and phantosmia (olfactory hallucinations). Olfactory impairment has a wide array of aetiologies and can also be a red flag for certain base of skull or intracranial malignancies. When chronic, olfactory impairment can have implications for morbidity and mortality due to complications such as malnourishment or obesity. It may have significant effects on functional capacity while also affecting general quality of life.

Epidemiological studies have shown olfactory impairment to be as common as $25 \%$ in people over the age of 53 years. ${ }^{1,2}$ It has a significant predilection for the geriatric population, with more than $50 \%$ of people over the age of 80 years affected. ${ }^{3}$ Olfactory testing is usually not included in routine health examinations in general practice, with self-reported olfactory impairment being the usual presentation. ${ }^{4}$ The subtle and insidious nature of olfactory impairment may play a part in underdiagnosis. ${ }^{1,5-7}$

\section{Aetiology}

The most common cause of olfactory impairment at a population level is the spectrum of age-related physiological changes. These changes are often irreversible and are commonly unrecognised by the geriatric population..$^{8,9}$ The most common causes for presentation in the general practice setting are rhinosinusitis, post-upper respiratory tract infection (URTI) and post-traumatic brain injury (TBI). ${ }^{4}$

\section{Obstructive sinonasal disease}

Obstructive causes of olfactory impairment generally have a good prognosis as they are easy to diagnose and reverse. This category predominantly relates to rhinosinusitis, which can have an allergic, viral or bacterial component. It results in inflammation of the sinonasal tract, producing impaired laminar airflow, oedematous mucosa, turbinate congestion and the formation of obstructive nasal polyposis, all of which can impair olfactory receptibility. Rhinosinusitis usually causes transient and incomplete olfactory 
impairment and has a good response to intranasal and systemic corticosteroid treatment. Other obstructive causes include neoplasms of the paranasal sinus and nasal cavity, which are important differentials to exclude.

\section{Sensorineural disease}

URTI remains the most common reason for presentation with olfactory impairment. Up to $26 \%$ of patients with olfactory impairment presenting to specialised smell and taste clinics will have a diagnosis related to a recent URTI. ${ }^{10}$ This is hypothesised to result from specific neurotropic viruses attacking olfactory neurones. ${ }^{11}$ Among common community viruses, COVID-19 is also implicated. Fortunately, the regenerative properties of the olfactory nervous system result in more than a third of patients experiencing spontaneous recovery over a year. ${ }^{12-14}$

Intracranial neoplasms in the vicinity of the olfactory tract may cause sensorineural olfactory impairment due to compression of associated nerves. These pathologies will usually present with an array of neurological signs and symptoms. A meningioma of the anterior cranial fossa may compress the olfactory tract and the optic nerve, resulting in a combination of olfactory impairment and visual disturbance. Primary neoplasms of the olfactory tract itself are exceedingly rare.

\section{Post-traumatic brain injury \\ Olfactory impairment is present in approximately $10-30 \%$ of TBIs. ${ }^{15-18}$ Post-traumatic olfactory impairment can result from facial injuries or from injuries to the brain - specifically to the frontal or temporal lobes. Acceleration-deceleration forces from blunt trauma can lead to shearing of olfactory nerves passing through the cribriform plate. Importantly, symptoms of clear rhinorrhoea are suggestive of cerebrospinal leakage and may indicate a cribriform plate fracture. There is no standardised treatment for patients with TBI. Prognosis remains poor, with only $10 \%$ of patients following TBI seeing improvements within two years of injury. ${ }^{12}$}

\section{Neuropsychiatric disorders}

The majority of patients with neurodegenerative diseases such as Parkinson's disease or Alzheimer's disease will experience varying degrees of olfactory impairment, which commonly occurs prior to the onset of other signs and symptoms. ${ }^{19-22}$ Differentiating this form of olfactory impairment from other age-related olfactory impairment can be difficult. Transient changes in smell can also be a feature of migraine aura or of temporal lobe seizures. The association between psychiatric illnesses and olfactory impairment is well documented. ${ }^{23}$ Patients with psychotic disorders often have trouble with smell identification secondary to a dysfunctional limbic system. ${ }^{24}$

\section{Toxins and medications}

Chronic toxin exposure may be indolent and difficult to diagnose as patients may become accustomed to their acquired olfactory impairment. The most common cause of toxin-induced olfactory impairment is chronic smoking. ${ }^{1}$ Fortunately, smoking cessation can frequently result in resolution of symptoms. ${ }^{25}$ Nasal insufflation of illicit drugs such as cocaine or ketamine can also have profound effects on the integrity of the nasal mucosa. Industrial inhalation of toxins can also cause olfactory impairment, with a full list of implicated toxins detailed in Table $1 .{ }^{26}$ Chemosensory side effects of prescription medication are often overlooked. Large numbers of prescription medications can cause varying degrees of olfactory impairment, as detailed in Table $1 .{ }^{27}$

\section{Congenital causes}

Congenital causes of olfactory impairment are exceedingly rare. The most common forms are related to hereditary diseases such as Kallman syndrome and primary ciliary dyskinesia.

\section{Table 1. Medications and toxins implicated in olfactory impairment}

\begin{tabular}{|c|c|c|}
\hline & Classification & Examples \\
\hline \multirow[t]{2}{*}{ Toxins } & Illicit drugs & Cocaine, ketamine \\
\hline & Industrial toxins & $\begin{array}{l}\text { Ash, nickel, paint solvents, formaldehyde, } \\
\text { chalk, cadmium, benzene, chromium }\end{array}$ \\
\hline \multirow[t]{10}{*}{ Medications } & Antibacterials & $\begin{array}{l}\text { Penicillins, azithromycin, ciprofloxacin, } \\
\text { clarithromycin, metronidazole, } \\
\text { sulfamethoxazole, tetracycline }\end{array}$ \\
\hline & Antifungals & Terbinafine \\
\hline & Antivirals & $\begin{array}{l}\text { Acyclovir, oseltamivir, highly active } \\
\text { antiretroviral therapies }\end{array}$ \\
\hline & Antihypertensives & $\begin{array}{l}\text { Amiodarone, diltiazem, amlodipine, } \\
\text { nifedipine, propranolol, spironolactone, } \\
\text { furosemide }\end{array}$ \\
\hline & Psychiatric medications & $\begin{array}{l}\text { Lithium, alprazolam, buspirone, clozapine, } \\
\text { paroxetine, amitriptyline }\end{array}$ \\
\hline & Thyroid medications & Carbimazole, propylthiouracil \\
\hline & Antiepileptics & Carbamazepine, phenytoin, topiramate \\
\hline & Antineoplastics & $\begin{array}{l}\text { Cisplatin, fluorouracil, methotrexate, } \\
\text { cyclophosphamide }\end{array}$ \\
\hline & Anticholinergics & Amitriptyline \\
\hline & Antiparkinsonians & Levodopa \\
\hline
\end{tabular}




\section{Complications of olfactory impairment}

Chronic olfactory impairment is a disease with significant biopsychosocial consequences. Patients often experience a lack of palatability for food and can experience disordered eating, with the most significant consequence being food avoidance and malnutrition. Malnutrition in the elderly contributes to frailty and impaired immunity, and it increases overall morbidity and mortality, especially in the context of other illnesses. On the other end of the spectrum, to satisfy cravings, some patients may attempt to binge eat or over-season foods with salts, sugars and fats, which can contribute to obesity and the acceleration of cardiovascular disease.

Chronic olfactory impairment can also cause disabilities in day-to-day living. Patients may fail to notice poor self-hygiene, which can place a strain on relationships and contribute to social isolation. Chemosensory deficits can also result in a higher risk of household hazards. ${ }^{28}$ Patients may fail to recognise expired foods or detect environmental dangers such a gas leaks or fire.

\section{History-taking}

During the history-taking, prompting questions to help characterise the olfactory impairment include:

- 'Does your nose feel blocked?'

- 'How different is your sense of smell now in comparison to when you were 25 years old?'

Asking, 'Do you ever smell odours for which you cannot find the cause?' can assist in identifying phantosmia.

Timing and acuity of symptoms can also provide insight into the cause of olfactory impairment. Persistent symptoms are suggestive of anatomical abnormalities, traumatic brain injury or neuropsychiatric disorders. Acute symptoms are suggestive of rhinosinusitis or post-URTI.

Both olfactory and gustatory impairment can present as a reduced sense of flavour in food and should be differentiated in the history-taking. Gustatory impairment is distinct from olfactory impairment in that patients often have an inability to discern some or all the basic tastes (salt, sweet, sour and bitter). Olfactory impairment can somewhat mimic gustatory impairment; however, patients generally report more generalised changes in taste, described as blandness and a general lack of palatability for food. An important discerning factor will be the inability to perceive odours without the presence of foods. ${ }^{29}$

Symptoms of rhinosinusitis/nasal polyposis include nasal obstruction, nasal discharge/postnasal drip, facial pain, headaches, malaise and fevers.

Other risk factors worth exploring include:

- previous TBI

- recent URTI

- atopy and allergic rhinitis

- newly commenced medications

- previous cancer

- previous strokes

- occupational exposure to toxins and illicit drugs

- migraines or seizures.

\section{Physical examination}

The easiest way to detect olfactory impairment is with the use of a single-odour coffee bean smell test, which has been shown to have a high sensitivity. ${ }^{30}$ This can be performed by placing coffee granules in a covered perforated cup followed by asking the patient to obstruct one side of the nostrils and sniff in. A comprehensive nasal, pharyngeal and oral examination should also be performed, which includes the use of a nasal speculum.

Other targeted examinations that can be conducted include a cranial nerve examination to assess for intracranial pathology, a mini-mental state examination in patients with suspected neurodegenerative disorders and biometric assessment such as body mass index to assess for malnutrition.

\section{Investigations}

Laboratory testing should be guided by history and examination, such as white cell count in suspected infection or blood biochemistry to assess for electrolyte abnormalities, low albumin and vitamin deficiencies in those with suspected malnutrition. High-resolution computed tomography scanning of the sinus can identify rhinosinusitis and exclude obstructive masses or anatomical anomalies. Magnetic resonance imaging should not be routinely ordered unless under specialist guidance. ${ }^{31}$

\section{Management}

A thorough history and examination in most cases can diagnose the common causes of olfactory impairment. First-line treatments in those with rhinosinusitis include nasal douching, intranasal and/or systemic corticosteroids and antibiotics as required..$^{32}$ There is good evidence for repeated scent exposure training in the management of sensorineural aetiologies as it improves the regeneration of olfactory mucosa and enhances the recovery of scent recognition and identification. A program is generally completed over a four-month period, and specific scents used include rose, eucalyptus, lemon and cloves. ${ }^{33-35}$

Newly prescribed medications should be reviewed to exclude medicationinduced olfactory impairment. In addition, guiding patients through smoking cessation is imperative. If initial treatments are ineffective or the diagnosis is unclear, referral to an ear, nose and throat (ENT) specialist would be appropriate as they can perform a nasoendoscopy and guide further investigation and management. Given the varied aetiology and the biopsychosocial implications of the disease, a multidisciplinary approach can often be helpful, with suggested speciality and allied health services detailed in Table 2 .

\section{Patient counselling}

Unfortunately, many causes of olfactory impairment are irreversible. Patients with chronic olfactory impairment should be counselled on lifestyle modifications to help with risk minimisation.

Recommendations can be provided on food expiration labelling and installation of gas/smoke alarms for patient safety. If patients display poor palatability for food, monosodium glutamate flavouring can improve the savoury 'umami' taste of food and is a good alternative to the use of excessive sugars and salts. 
Additionally, patients can be advised to chew food thoroughly to enhance the release of flavours. There should also be an assessment for the potential psychosocial effects of olfactory impairment.

\section{Key points}

- Olfactory impairment is highly prevalent in the geriatric population.

- The most common causes of olfactory impairment include URTI, head trauma and rhinosinusitis. Rhinosinusitis is readily treatable and has an excellent prognosis.

- The exclusion of COVID-19 in patients with anosmia is recommended.

- A thorough history and diagnosis can usually allow for a diagnosis of the common causes.

- A flexible nasoendoscopy performed by an ENT specialist can exclude many red flags.

- Chronic olfactory impairment can be a disabling disease, and patients may require adaptive lifestyle counselling and psychosocial support.

\section{Authors}

Fred Chuang MD, MBS, Principal House Officer, Gold Coast University Hospital, Qld

\section{Table 2. Useful speciality and allied health services for the management} of olfactory impairment

Specialist and allied

health services

Indications for referral

\begin{tabular}{ll}
\hline Ear, nose and throat specialist & - Unclear diagnosis \\
& - Persistent chronic rhinosinusitis \\
& - Obstructive sinonasal lesions \\
& - Septal/nasal deformity \\
& - Base of skull tumours \\
\hline Dietitian & - Signs or risk factors for malnutrition \\
& - Poor palatability for food \\
\hline Geriatrician & Binge-eating behaviours or significant weight gain \\
\hline Neurologist & - Evidence of neurodegenerative disorders \\
\hline Psychologist & - Meneralised frailty and psychosocial decline \\
\hline
\end{tabular}

\begin{tabular}{ll}
\hline Ear, nose and throat specialist & - Unclear diagnosis \\
& - Persistent chronic rhinosinusitis \\
& - Obstructive sinonasal lesions \\
& - Septal/nasal deformity \\
& - Base of skull tumours \\
\hline Dietitian & - Signs or risk factors for malnutrition \\
& - Poor palatability for food \\
\hline Geriatrician & Binge-eating behaviours or significant weight gain \\
\hline Neurologist & - Evidence of neurodegenerative disorders \\
\hline Psychologist & - Meneralised frailty and psychosocial decline \\
\hline
\end{tabular}

Rohan Arasu MBBS, GDipSurgAnat, Principal House Officer, Townsville Hospital, Qld

Benjamin Wallwork MBBS (Hons), FRACS, PhD, ENT Consultant, Princess Alexandra Hospital, Qld

Competing interests: None.

Provenance and peer review: Not commissioned, externally peer reviewed.

Correspondence to:

fred_ch@live.com

\section{References}

1. Murphy C, Schubert CR, Cruickshanks KJ, Klein BE, Klein R, Nondahl DM. Prevalence of olfactory impairment in older adults. JAMA 2002;288(18):2307-12. doi: 10.1001/

Bramerson A, Johansson L, Ek L, Nordin S,

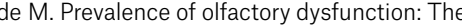
Skovde population-based study. Laryngoscope 2004:114(4):733-37. doi: 10.1097/00005537-

Doty $\mathrm{RL}$ Kamath $\mathrm{V}$. The influences of age on olfaction: A review. Front Psychol 2014;5:20.

Nordin S, Bramerson A. Complaints of and clinical implications. Curr Opin Allergy Clin Immunol 2008;8(1):10-15. doi: 10.1097/ ACl.0b013e3282f3f473.

5. Adams DR, Wroblewski KE, Kern DW, et al. Factors associated with inaccurate self-reporting of olfactory dysfunction in older US adults. Chem Senses 2017;42(3):223-31. doi: 10.1093/chemse/bjw108.

Landis BN, Konnerth CG, Hummel T. A study on the frequency of olfactory dysfunction. (2004:114(10):1764-69. doi: 10.1097/00005537-200410000-00017.

7. Kang JW, Lee YC, Han K, Kim SW, Lee KH Epidemiology of anosmia in South Korea: jama.288.18.2307.
A nationwide population-based study. Sci Rep 2020;10(1):3717. doi: 10.1038/s41598-020-60678-z.

8. Boyce JM, Shone GR. Effects of ageing on smell and taste. Postgrad Med J 2006;82(966):239-41. doi: 10.1136/pgmj.2005.039453.

9. Doty RL, Shaman P, Applebaum SL, Giberson R, Siksorski L, Rosenberg L. Smell identification ability: Changes with age. Science 1984;226(4681):1441-43. doi: 10.1126/ science.6505700

10. Seiden AM. Postviral olfactory loss. Otolaryngol Clin North Am 2004;37(6):1159-66. doi: 10.1016/j. otc.2004.06.007

11. Suzuki M, Saito K, Min WP, et al. Identification of viruses in patients with postviral olfactory dysfunction. Laryngoscope 2007;117(2):272-77. doi: 10.1097/01.mlg.0000249922.37381.1e.

12. Reden J, Mueller A, Mueller C, et al. Recovery of olfactory function following closed head injury or infections of the upper respiratory tract. Arch Otolaryngol Head Neck Surg 2006;132(3):265-69. doi: 10.1001/archotol.132.3.265.

13. Seo BS, Lee HJ, Mo JH, Lee CH, Rhee CS, Kim JW. Treatment of postviral olfactory loss with glucocorticoids, Ginkgo biloba, and mometasone nasal spray. Arch Otolaryngol Head Neck Surg 2009;135(10):1000-04. doi: 10.1001/ archoto.2009.141.

14. Duncan HJ, Seiden AM. Long-term follow-up of olfactory loss secondary to head trauma and upper respiratory tract infection. Arch Otolaryngol Head Neck Surg 1995;121(10):1183-87. doi: 10.1001/ archotol.1995.01890100087015.

15. Doty RL, Yousem DM, Pham LT, Kreshak AA Geckle R, Lee WW. Olfactory dysfunction in patients with head trauma. Arch Neurol 1997:54(9):1131-40. doi: 10.1001/ archneur.1997.00550210061014.

16. Howell J, Costanzo RM, Reiter ER. Head trauma and olfactory function. World J Otorhinolaryngol Head Neck Surg 2018;4(1):39-45. doi: 10.1016/j. wjorl.2018.02.001.

17. Proskynitopoulos PJ, Stippler M, Kasper EM. Posttraumatic anosmia in patients with mild traumatic brain injury (mTBI): A systematic and illustrated review. Surg Neurol Int 2016;7(Suppl 10):S263-75. doi: 10.4103/2152-7806.181981.

18. Atighechi $S$, Salari $H$, Baradarantar $M H$, Jafari $R$, Karimi G, Mirjali M. A comparative study of brain perfusion single-photon emission computed tomography and magnetic resonance imaging in patients with post-traumatic anosmia. Am J Rhinol Allergy 2009;23(4):409-12. doi: 10.2500/ ajra.2009.23.3345.

19. Alves J, Petrosyan A, Magalhaes R. Olfactory dysfunction in dementia. World J Clin Cases 2014;2(11):661-67. doi: 10.12998/wjcc.v2.i11.661.

20. Haehner A, Hummel T, Reichmann H. Olfactory loss in Parkinson's disease. Parkinsons Dis 2011;2011:450939. doi: 10.4061/2011/450939.

21. Nordin S, Paulsen JS, Murphy C. Sensory- and memory-mediated olfactory dysfunction in Huntington's disease. J Int Neuropsychol Soc 1995:1(3):281-90. doi: 10.1017/ s1355617700000278.

22. Marine N, Boriana A. Olfactory markers of depression and Alzheimer's disease. Neurosci Biobehav Rev 2014;45:262-70. doi: 10.1016/j. neubiorev.2014.06.016.

23. Kohli P, Soler ZM, Nguyen SA, Muus JS, Schlosser RJ. The association between olfaction and depression: A systematic review. Chem Senses 2016;41(6):479-86. doi: 10.1093/chemse/ bjw061. 
24. Turetsky BI, Hahn CG, Borgmann-Winter K, Moberg PJ. Scents and nonsense: Olfactory dysfunction in schizophrenia. Schizophr Bull 2009;35(6):1117-31. doi: 10.1093/schbul/sbp111.

25. Frye RE, Schwartz BS, Doty RL. Dose-related effects of cigarette smoking on olfactory function. JAMA 1990;263(9):1233-36.

26. Doty RL. Neurotoxic exposure and impairment of the chemical senses of taste and smell. Handb

Clin Neurol 2015;131:299-324. doi: 10.1016/B9780-444-62627-1.00016-0.

27. Schiffman SS. Influence of medications on taste and smell. World J Otorhinolaryngol Head Neck Surg 2018;4(1):84-91. doi: 10.1016/j. wjorl.2018.02.005.

28. Santos DV, Reiter ER, DiNardo LJ, Costanzo RM. Hazardous events associated with impaired olfactory function. Arch Otolaryngol Head Neck Surg 2004;130(3):317-19. doi: 10.1001/ archotol.130.3.317.

29. Maheswaran T, Abikshyeet P, Sitra G, Gokulanathan S, Vaithiyanadane V, Jeelani S. Gustatory dysfunction. J Pharm Bioallied Sci 2014;6(Suppl 1):S30-33. doi: 10.4103/09757406.137257.

30. Singh R, Humphries T, Mason S, Lecky F, Dawson J, Sinha S. The incidence of anosmia after traumatic brain injury: The SHEFBIT cohort. Brain Inj 2018;32(9):1122-28. doi: 10.1080/02699052.2018.1483028.

31. Busaba NY. Is imaging necessary in the evaluation of the patient with an isolated complaint of anosmia? Ear Nose Throat J 2001;80(12):892-96.

32. Scangas GA, Bleier BS. Anosmia: Differential diagnosis, evaluation, and management. Am J Rhinol Allergy 2017;31(1):3-7. doi: 10.2500/ ajra.2017.31.4403.
33. Hummel T, Rissom K, Reden J, Hahner A, Weidenbecher M, Huttenbrink KB. Effects of olfactory training in patients with olfactory loss. Laryngoscope 2009;119(3):496-99. doi: 10.1002/ lary.20101.

34. Sorokowska A, Drechsler E, Karwowski M, Hummel T. Effects of olfactory training: A metaanalysis. Rhinology 2017;55(1):17-26. doi: 10.4193/ Rhin16.195.

35. Damm M, Pikart LK, Reimann H, et al. Olfactory training is helpful in postinfectious olfactory loss: A randomized, controlled, multicenter study. Laryngoscope 2014;124(4):826-31. doi: 10.1002/ lary.24340. 